\title{
A study on knowledge and practice of neonatal resuscitation among nursing staff
}

\author{
Manjari Basu ${ }^{1}$
}

Sri Lanka Journal of Child Health, 2014; 43(1): 38-40

\begin{abstract}
Birth asphyxia is a major cause of global neonatal death. One of the effective measures to prevent these deaths is to have skilled birth attendants in neonatal resuscitation. Several trials have shown that basic neonatal training can decrease neonatal deaths. My study is a cross-sectional observational study to determine the knowledge and practice about neonatal resuscitation among nursing staff working in up to secondary level care.
\end{abstract}

(Key words: neonatal resuscitation; birth asphyxia)

\section{Introduction}

India accounts for nearly 0.9 million newborn deaths per year i.e. $30 \%$ of global neonatal deaths. Two major causes of these deaths are birth asphyxia and sepsis. One effective measure to prevent these deaths is to have skilled birth attendants in neonatal resuscitation. Unfortunately, most nursing staff and other health care providers have never received any intensive training in neonatal resuscitation and have traditional beliefs regarding this. A nationwide training programme on neonatal resuscitation in China decreased intrapartum related deaths from 7.5 to 3.4 per $10,000^{1}$. Moreover, several trials have shown that basic neonatal resuscitation training decreases neonatal deaths up to $20 \%$ in low-resource settings ${ }^{2}$.

\section{Objective}

To determine knowledge and practice about neonatal resuscitation among nursing staff working in up to secondary level care.

\section{Method}

Study type: Cross-sectional observational study.

${ }^{1}$ Assistant Professor, Department of Paediatrics, College of Medicine and JNM Hospital, The West Bengal University of Health Sciences, India

(Received on 15 June 2013: Accepted after revision on 9 August 2013)
Setting: The study was conducted in the Department of Paediatrics of University College of Medicine and JNM Hospital, Kalyani, West Bengal, India.

Participants: The delivery rate at Kalyani town is on the average around 9 thousand per year. The total number of nursing staff in that area is 240 . The study consisted of $116(48.3 \%)$ nursing staff of primary health centre and hospitals with secondary level neonatal care in and around Kalyani town. They had no intensive training in neonatal resuscitation in the recent past.

Material: A theory and practical examination were taken. For the written test a questionnaire consisting of 20 questions was used. The questions were divided into 4 steps according to neonatal resuscitation viz. preparation of equipment, initial steps of resuscitation, ventilation and chest compression. Endotracheal intubation and use of medications were excluded as they are not included in basic newborn care. The questions were derived from the American Heart Association/American Academy of Paediatrics Textbook of Neonatal Resuscitation.

In the practical test performance, evaluation was done in 4 parts:

a. Preparation of personnel, equipment and supplies.

b. Initial steps of resuscitation.

c. Positive pressure ventilation.

d. Chest compression.

For b, c, d, points on indication, procedure and duration were included.

Procedure: The participants appeared first for the written test under standardized strictly supervised conditions, and were required to complete the test in 20 minutes. The questions were of the True / False type. Then practical tests were taken individually in 4 tables. Those who scored $>85 \%$ were scored as successful.

Statistical calculation: All numeric values are expressed exact number (n) or percentages (\%). 


\section{Results}

In the theory paper 20 questions in 4 parts were given to nursing staff. Each part contained 5 questions. Percentage of correct answers in each part is given in Table I.

Table I: Answers to 20 questions in 4 parts given by nursing staff $(n=116)$

\begin{tabular}{|l|l|c|}
\hline \multicolumn{1}{|c|}{ Subject } & No. of correct answers & Number (\%) \\
\hline Preparation of personnel, equipment & 5 answers are correct & $05(04.3)$ \\
& 4 correct & $06(05.2)$ \\
& 3 correct & $55(47.4)$ \\
& 2 correct & $45(38.8)$ \\
& 1 correct & $01(00.9)$ \\
& 0 correct & $04(03.4)$ \\
\hline Initial steps of resuscitation & 5 answers are correct & $02(01.7)$ \\
& 4 correct & $20(17.2)$ \\
& 3 correct & $72(62.1)$ \\
& 2 correct & $10(08.6)$ \\
& 1 correct & $08(06.9)$ \\
& 0 correct & $04(03.4)$ \\
\hline Positive pressure ventilation & 5 answers are correct & $01(00.9)$ \\
& 4 correct & $05(04.3)$ \\
& 3 correct & $72(62.1)$ \\
& 2 correct & $11(09.5)$ \\
& 1 correct & $17(14.7)$ \\
& 0 correct & $10(08.6)$ \\
\hline & 5 answers are correct & $02(01.7)$ \\
& 4 correct & $04(03.4)$ \\
& 3 correct & $72(62.1)$ \\
& 2 correct & $12(10.3)$ \\
& 1 correct & $16(13.8)$ \\
& 0 correct & $10(08.6)$ \\
\hline
\end{tabular}

Practical test on performance evaluation was done on the basis of above mentioned 4 parts. Examiners were given a list of 16 items and scoring was done on as $0=$ not done; $1=$ done incorrectly or incompletely; 2 = done correctly in order (table 2). 
Table 2: Practical test on performance evaluation of the 116 nursing staff

\begin{tabular}{|c|c|c|c|}
\hline Item $(n=16)$ & Zero score: No. $(\%)$ & 1 score: No. $(\%)$ & 2 score: No. $(\%)$ \\
\hline Demonstrates preparation of personnel & $04(03.4)$ & $98(84.5)$ & $14(12.1)$ \\
\hline Check bag, mask & $05(04.3)$ & $100(86.2)$ & $11(09.5)$ \\
\hline $\begin{array}{l}\text { If meconium present, baby not crying, } \\
\text { carries out suction first }\end{array}$ & $35(30.2)$ & $71(61.2)$ & $10(08.6)$ \\
\hline Dries, removes wet towel & $04(03.4)$ & $90(77.6)$ & $22(19.0)$ \\
\hline Wraps with warm towel & $09(07.8)$ & $76(65.5)$ & $31(26.7)$ \\
\hline $\begin{array}{l}\text { If baby not crying, positions baby, clears } \\
\text { mouth and then nose }\end{array}$ & $00(00)$ & $114(98.3)$ & $02(01.7)$ \\
\hline Stimulates to breathe and repositions baby & $00(00)$ & $114(98.3)$ & $02(01.7)$ \\
\hline Assess for breathing & $04(03.4)$ & $02(01.7)$ & $110(94.8)$ \\
\hline $\begin{array}{l}\text { Indicates need for positive pressure } \\
\text { ventilation }\end{array}$ & $04(03.4)$ & $02(01.7)$ & $110(94.8)$ \\
\hline Applies facemask correctly & $20(17.2)$ & $90(77.6)$ & $06(05.2)$ \\
\hline Looks and asks if the chest is rising & $92(79.3)$ & $22(19.0)$ & $02(01.7)$ \\
\hline $\begin{array}{l}\text { Takes corrective action if chest rise is } \\
\text { not adequate }\end{array}$ & $92(79.3)$ & $23(19.8)$ & $01(0.86)$ \\
\hline $\begin{array}{l}\text { Ventilate with appropriate rate and } \\
\text { pressure }\end{array}$ & $92(79.3)$ & $23(19.8)$ & $01(0.86)$ \\
\hline Counts heart rate in 6 seconds & $20(17.2)$ & $94(81.0)$ & $02(01.7)$ \\
\hline Takes action according to heart rate & $80(69.0)$ & $34(29.3)$ & $02(01.7)$ \\
\hline $\begin{array}{l}\text { Chest compression in proper position } \\
\text { and method }\end{array}$ & $92(79.3)$ & $22(19.0)$ & $02(01.7)$ \\
\hline
\end{tabular}

\section{Discussion}

From table 1 it is found that the nursing staff has average knowledge in all 4 steps and in all, correct answers to step 3 have the highest percentage. However, in the practical test the results were different. In preparation of equipment they have average incomplete practice. In initial steps of resuscitation all participants have done something but most have done it incorrectly or incompletely. However there was very poor performance in last 2 steps viz. positive pressure ventilation and chest compression. Most (79.3\%) of them knew nothing about how to do positive pressure ventilation or chest compression. Rest knew it incorrectly. Only one or two participants knew it perfectly. Moreover, we got the impression that in last 2 steps they have average knowledge from books but no practical experience in their working field.

In resource poor areas, in difficult territories, paediatricians are rarely available to attend emergency deliveries. There, nursing staffs are the medical persons available to do neonatal resuscitation. However, in this study it is found that though they have some theoretical knowledge they have very poor practical knowledge in using bag-mask ventilation and chest compression. Thus, workshops are needed on 'hands on' demonstration of the first one minute of neonatal resuscitation for the nursing staff.

\section{References}

1. Xie T, Wang HS, Ye HM, Yu RJ, Huang XH, Wang DH et al. Impact of a nationwide training program for neonatal resuscitation in China. Chinese Medical Journal 2012; 125(8): 1448-56.

2. Wall SN, Lee A CC, Niermeyers, English M, Keenam WJ, Carlo W et al. Neonatal resuscitation in low-resource setting: What, who and how to overcome challenges to scale up? International Journal of Gynecology and Obstetrics 2009; 107(Suppl. 1): s47-64. http://dx.doi.org/10.1016/j.ijgo.2009.07.013

3. Murila F, Obimbo MM, Musoke R. Assessment of knowledge on neonatal resuscitation amongst health care providers in Kenya. Pan African Medical Journal 2012; 11:78. 